\title{
Biochemical markers of cardiac dysfunction predict mortality in acute exacerbations of COPD
}

\author{
Catherina L Chang, ${ }^{1}$ Scott C Robinson, ${ }^{2}$ Graham D Mills, ${ }^{3}$ Glenda D Sullivan, ${ }^{1}$ \\ Noel C Karalus, ${ }^{1}$ John D McLachlan, ${ }^{1}$ Robert J Hancox ${ }^{1,4}$
}

\section{See Editorial, p 745}

- Additional materials are published online only. To view these files please visit the journal online (http://thorax.bmj. com).

${ }^{1}$ Respiratory Research Unit, Department of Respiratory Medicine, Waikato Hospital, New Zealand

${ }^{2}$ Department of Anaesthesia, Waikato Hospital, New Zealand ${ }^{3}$ Department of General Medicine, Waikato Hospital, New Zealand

${ }^{4}$ Department of Preventive \& Social Medicine, University of Otago, Dunedin, New Zealand

\section{Correspondence to} Dr Catherina L Chang, Department of Respiratory Medicine, Waikato Hospital, Level 01 Menzies Building, Hamilton 3204, New Zealand; contact_cat@hotmail.com

Received 9 November 2010 Accepted 3 March 2011 Published Online First 7 April 2011

\section{ABSTRACT \\ Background Retrospective studies suggest that} plasma levels of $\mathrm{N}$-terminal pro-brain natriuretic peptide (NT-proBNP) and cardiac troponin T are often elevated in patients with acute exacerbations of chronic obstructive pulmonary disease (COPD) and are associated with increased mortality. These cardiac biomarkers were investigated in an unselected cohort of patients admitted to hospital with exacerbations of COPD.

Methods Consecutive patients with physician-diagnosed COPD exacerbation but without clinical evidence of acute cardiac disease admitted to a public hospital over a 1 year period were studied prospectively. NT-proBNP and troponin T were measured on admission. The primary end point was all-cause mortality at 30 days.

Results Elevated NT-proBNP (>220 pmol/l) was present in 65/244 patients (27.5\%) and significantly predicted 30-day mortality (OR $9.0,95 \% \mathrm{Cl} 3.1$ to 26.2 , $\mathrm{p}<0.001)$. Elevated troponin $\mathrm{T}(>0.03 \mu \mathrm{g} / \mathrm{l})$ was found in 40/241 patients (16.6\%) and also predicted 30-day mortality (OR 6.3, 95\% Cl 2.4 to $16.5, p<0.001$ ). These associations persisted after adjusting for other clinical and laboratory predictors of mortality (arterial $\mathrm{CO}_{2}$ pressure $\left(\mathrm{PaCO}_{2}\right)$, body mass index and CURB65 score). NT-proBNP and troponin T levels appeared to have additive associations with mortality: 30-day mortality among patients with abnormalities of both NT-proBNP and troponin $T$ was 15-fold higher than among patients with normal values.

Conclusion Elevated levels of NT-proBNP and troponin $T$ are strong predictors of early mortality among patients admitted to hospital with acute exacerbations of COPD independently of other known prognostic indicators. The pathophysiological basis for this is unknown, but indicates that cardiac involvement in exacerbations of COPD may be an important determinant of prognosis.

\section{INTRODUCTION}

Cardiovascular disease is common in patients with chronic obstructive pulmonary disease (COPD) and is associated with poorer prognosis in COPD exacerbations. ${ }^{1} 2$ The degree to which cardiac disease contributes to mortality during exacerbations of COPD is unknown, but accumulating evidence suggests that this may be substantial. Severe hypoxaemia, pulmonary hypertension and systemic inflammation due to exacerbations of COPD may impact on cardiac function, but the interplay of these factors and their cardiovascular effects in COPD is incompletely understood. ${ }^{3} 4$

\section{Key messages}

What is the key question?

- Does subclinical cardiac involvement influence mortality in acute exacerbation of COPD?

\section{What is the bottom line?}

- Elevated levels of NT-proBNP and troponin T strongly predict 30-day mortality in patients with acute exacerbations of COPD independently of other markers of severity and prognosis.

\section{Why read on?}

- The findings from this prospective study of cardiac biomarkers in COPD exacerbation suggest that we may need to re-think the causes of death in these patients.

Brain natriuretic peptide (BNP) and N-terminal pro-BNP (NT-proBNP) are established markers of left ventricular dysfunction and are associated with increased mortality in acute and stable heart disease. ${ }^{5} 6$ They are also increased with right ventricular overload and associated with a poor prognosis in pulmonary arterial hypertension and pulmonary thromboembolism. ${ }^{7-9}$

Cardiac troponins are specific markers of myocardial necrosis and commonly used to diagnose myocardial infarction. ${ }^{10}$ Elevated troponin levels may also occur in pulmonary thromboembolism, congestive heart failure, tachyarrhythmias, myocarditis, pericarditis, sepsis and stroke. ${ }^{11}$ Troponin elevations in these conditions probably reflect general myocardial injury rather than coronary arterial occlusion. We have retrospectively observed that cardiac troponins are frequently raised in COPD exacerbations and appear to be associated with the severity of the exacerbation. ${ }^{12}$ There are few prospective data on the prognostic value of cardiac troponins in patients with exacerbations of COPD.

To investigate cardiac involvement in acute COPD exacerbations, we prospectively analysed the associations between NT-proBNP and troponin $\mathrm{T}$ levels and mortality in a prospective cohort of consecutive patients admitted to hospital with exacerbations of COPD.

\section{MATERIALS AND METHODS}

Detailed methods are given in the online supplement.

Consecutive patients admitted to Waikato Hospital with exacerbations of COPD over 1 year 
were recruited. Patients were excluded if there was evidence of another acute respiratory illness (such as acute asthma or pneumonia) or if the main reason for hospitalisation was not COPD exacerbation. Patients diagnosed with coronary ischaemia were excluded. For patients admitted more than once during the study period, only the first admission was included in the analysis. Treatment was not influenced by participation in the study. Medical history and physiological variables were recorded on admission. These data were used to compile two prognostic scores: BAP65 and CURB65. ${ }^{13} 14$ NT-proBNP and troponin $\mathrm{T}$ were measured within $24 \mathrm{~h}$ of admission and were categorised as normal or elevated according to local reference values. The primary end point was 30-day mortality. Mortality between 30 days and 1 year was a secondary end point. Logistic regression was used to adjust associations between NT-proBNP, troponin $\mathrm{T}$ and mortality for potential confounders including age, lung function, arterial blood gases, CURB65 score, BAP65 score and body mass index (BMI). Only variables with univariate associations of $\mathrm{p} \leq 0.05$ were included in the multiple logistic regression models. Mortality in patients with different cardiac marker status (normal; elevated NT-proBNP and normal troponin $\mathrm{T}$; normal NT-proBNP and elevated troponin $\mathrm{T}$; and both elevated NT-proBNP and troponin $\mathrm{T}$ ) was compared using $\chi^{2}$ tests.

\section{RESULTS}

Two hundred and fifty-one consecutive patients met the inclusion criteria, of whom 250 consented to participate (table 1). Survival information was available for 248 (99\%) at 30 days and 227 (91\%) at 1 year. Thirty-seven percent had very severe airway obstruction (forced expiratory volume in $1 \mathrm{~s}\left(\mathrm{FEV}_{1}\right)<30 \%$ predicted), 44\% had severe airway obstruction $\left(\mathrm{FEV}_{1} 30-50 \%\right.$ predicted) and $19 \%$ had mild/moderate airway obstruction. ${ }^{16}$ Lung function was not measured in seven patients due to inpatient death or inability to perform spirometry. Nine patients did not meet spirometric criteria for COPD. ${ }^{16}$ Excluding these patients from the analysis made no difference to the findings. The 30-day and 1-year mortality were 8.5\% (21/248) and 18.5\% $(42 / 227)$, respectively.

NT-proBNP levels were available for 244 (98\%) patients. The median level was $66.5 \mathrm{pmol} / 1$ (range 2-3900). Sixty-five patients had elevated levels (>220 pmol/l). Elevated NT-proBNP predicted mortality at 30 days (table 2 ) but did not predict deaths between 30 days and 1 year of follow-up $(p=0.27$ ) (figure 1). Analysed as a continuous variable using logistic regression, the $\mathrm{OR}$ of 30-day mortality associated with each SD increase of log-NT-proBNP was 2.6 (95\% CI, 1.542 to 4.432, p<0.001).

Troponin T levels were available for 241 (97\%) patients. Seventy-four percent were below the lower limit of detection at $0.01 \mu \mathrm{g} / \mathrm{l}$. The troponin T level was elevated $(>0.03 \mu \mathrm{g} / \mathrm{l})$ in 40 $(16.6 \%)$ patients. Elevated troponin $\mathrm{T}$ levels predicted mortality at 30 days (OR 6.3, $\mathrm{p}<0.001$ ) (table 2 ) but did not predict deaths between 30 days and 1 year of follow-up $(p=0.63)$ (figure 1$)$.

NT-proBNP and troponin T levels were correlated (Spearman $\mathrm{rho}=0.46, \mathrm{p}<0.001)$. In logistic regression analyses using both biomarkers, a raised NT-proBNP predicted 30-day mortality (OR $6.71, \mathrm{p}=0.001$ ), but raised troponin $\mathrm{T}$ levels were of borderline significance (OR 2.74, $p=0.066$ ). Patients with both raised troponin $\mathrm{T}$ and raised NT-proBNP had the highest risk of 30-day mortality (figure 2).

In univariate analyses, $\mathrm{pH}$, arterial $\mathrm{CO}_{2}$ pressure $\left(\mathrm{PaCO}_{2}\right), \mathrm{BMI}$ and CURB65 scores also predicted 30-day mortality, whereas lung function $\left(\mathrm{FEV}_{1} \%\right.$ predicted, $\mathrm{FEV}_{1} /$ forced vital capacity $(\mathrm{FVC})), \mathrm{PaO}_{2}, \mathrm{BAP} 65$ score and age did not. $\mathrm{PaCO}_{2}$ and $\mathrm{pH}$ were
Table 1 Cohort characteristics

\begin{tabular}{|c|c|}
\hline \multicolumn{2}{|l|}{$\overline{S e x}, \mathrm{n}(\%)$} \\
\hline Male & $112(45)$ \\
\hline Female & $138(55)$ \\
\hline \multicolumn{2}{|l|}{ Ethnicity (\%) } \\
\hline European & $197(79)$ \\
\hline Maori & $43(17)$ \\
\hline Other & $10(4)$ \\
\hline Age, mean in years (SD) & $71.7(10.6)$ \\
\hline European & $73(10.3)$ \\
\hline Maori & $67(9.9)$ \\
\hline \multicolumn{2}{|l|}{ Smoking status (\%) } \\
\hline Current smoker & $83(33)$ \\
\hline Ex-smoker & $159(63)$ \\
\hline Never & $8(3.2)$ \\
\hline \multicolumn{2}{|l|}{ Lung function-mean (SD) } \\
\hline $\mathrm{FEV}_{1}$ (litres) & $0.81(0.34)$ \\
\hline $\mathrm{FEV}_{1}(\% \text { predicted })^{*}$ & $35(15)$ \\
\hline $\mathrm{FEV}_{1} / \mathrm{FVC}(\%)$ & $44(14)$ \\
\hline $\mathrm{BMI}$-mean (SD) & $25.3 \mathrm{~kg} / \mathrm{m}^{2}(7.0)$ \\
\hline \multicolumn{2}{|l|}{ Co-morbidities, n (\%) } \\
\hline Renal insufficiency & $22(8.8)$ \\
\hline Malignancy & $23(9.2)$ \\
\hline Cardiovascular disease & $75(30.1)$ \\
\hline Cerebral vascular disease & $28(11.2)$ \\
\hline Liver disease & $2(0.8)$ \\
\hline None of the above & $141(56.6)$ \\
\hline \multicolumn{2}{|l|}{ Treatment, n (\%) } \\
\hline Systemic corticosteroids & $245(98)$ \\
\hline Antimicrobial therapy & $241(96)$ \\
\hline Bronchodilating agents & $250(100)$ \\
\hline Non-invasive ventilation & $24(9.6)$ \\
\hline Ventilation via endotracheal tube & $2(1)$ \\
\hline $\begin{array}{l}\text { Intensive/high dependency care } \\
\text { admission }\end{array}$ & $15(6.0)$ \\
\hline
\end{tabular}

highly correlated (Spearman rho $=0.76$ ) and did not predict mortality independently of each other. In multivariate analysis, a high NT-proBNP remained a significant predictor of 30-day mortality independently of $\mathrm{PaCO}_{2}$ (or pH), BMI and CURB65 score (table 2). A high troponin Twas also a significant predictor of 30-day mortality independently of $\mathrm{PaCO}_{2}$, BMI and CURB65 score, but failed to achieve statistical significance if NT-proBNP was included in the analysis (table 2). A past history of cardiovascular disease was associated with high NT-proBNP levels $\left(\chi^{2}=9.1, \quad p=0.003\right)$ but did not predict 30-day mortality. Troponin $\mathrm{T}$ levels were not associated with a past history of cardiac disease $\left(\chi^{2}=0.11, \mathrm{p}=0.74\right)$.

\section{DISCUSSION}

Elevated NT-proBNP and troponin T were strongly associated with increased early mortality in this unselected cohort of patients admitted to hospital with exacerbations of COPD. These biomarkers appeared to have an additive association with risk: patients with abnormalities of both NT-proBNP and troponin $\mathrm{T}$ had a 15 -fold higher mortality at 30 days thanpatients with normal values for both markers (figure 2). The pathophysiological processes underlying the derangements in these biomarkers and how they relate to increased mortality in exacerbations of COPD are unknown. However, patients without abnormalities of NT-proBNP or troponin $\mathrm{T}$ had a low mortality, and this suggests that cardiac involvement may be an important determinant of prognosis in COPD exacerbations. 
Table 2 Univariate and logistic regression analyses of risk factors for death at 30 days in patients hospitalised for acute exacerbation of chronic obstructive pulmonary disease

\begin{tabular}{|c|c|c|c|c|c|c|}
\hline \multirow[b]{2}{*}{ Variable } & \multicolumn{3}{|c|}{ Univariate analysis } & \multicolumn{3}{|c|}{ Multivariate logistic regression } \\
\hline & $\mathbf{O R}$ & p Value & $95 \% \mathrm{CI}$ & $\mathbf{O R}$ & p Value & $95 \% \mathrm{Cl}$ \\
\hline Age, years & 1.032 & 0.171 & 0.99 to 1.08 & & & \\
\hline BMI, $\mathrm{kg} / \mathrm{m}^{2}$ & 0.925 & 0.035 & 0.86 to 0.99 & 0.905 & 0.029 & 0.83 to 0.99 \\
\hline \multicolumn{7}{|l|}{ Lung function } \\
\hline $\mathrm{FEV}_{1}$, litres & 0.504 & 0.392 & 0.11 to 2.42 & & & \\
\hline$\%$ predicted $\mathrm{FEV}_{1}, \%$ & 0.998 & 0.923 & 0.97 to 1.03 & & & \\
\hline $\mathrm{FEV}_{1} / \mathrm{FVC}, \%$ & 1.0 & 0.998 & 0.96 to 1.04 & & & \\
\hline $\mathrm{PaCO}_{2}, \mathrm{~mm} \mathrm{Hg}$ & 1.049 & $<0.0001$ & 1.03 to 1.07 & 1.041 & 0.002 & 1.02 to 1.07 \\
\hline $\mathrm{PaO}_{2}, \mathrm{~mm} \mathrm{Hg}$ & 0.996 & 0.683 & 0.98 to 1.02 & & & \\
\hline CRP, mg/l & 1.05 & 0.949 & 0.99 to 1.07 & & & \\
\hline \multicolumn{7}{|l|}{ Clinical scores } \\
\hline BAP65, increment by 1 & 1.665 & 0.065 & 0.97 to 2.86 & & & \\
\hline CURB65, increment by 1 & 2.171 & $<0.0001$ & 1.42 to 3.32 & 1.684 & 0.075 & 0.95 to 2.98 \\
\hline \multicolumn{7}{|l|}{ Past medical history } \\
\hline Cardiovascular disease & 0.701 & 0.504 & 0.25 to 1.99 & & & \\
\hline Cerebral vascular disease & 1.990 & 0.248 & 0.62 to 6.40 & & & \\
\hline Malignancy & 0.466 & 0.467 & 0.06 to 3.64 & & & \\
\hline \multicolumn{7}{|c|}{ Biochemical markers of cardiac dysfunction } \\
\hline \multirow[t]{2}{*}{ NT-proBNP >220 pmol/l } & 9.034 & $<0.0001$ & 3.11 to 26.25 & 7.455 & 0.004 & 1.92 to 28.90 \\
\hline & & & & $9.241^{*}$ & 0.001 & 2.58 to 33.05 \\
\hline \multirow[t]{2}{*}{ Troponin $\mathrm{T}>0.03 \mu \mathrm{g} / \mathrm{l}$} & 6.333 & $<0.0001$ & 2.43 to 16.50 & 2.468 & 0.138 & 0.75 to 8.15 \\
\hline & & & & $5.115 \dagger$ & 0.003 & 1.73 to 15.15 \\
\hline \multicolumn{7}{|c|}{ 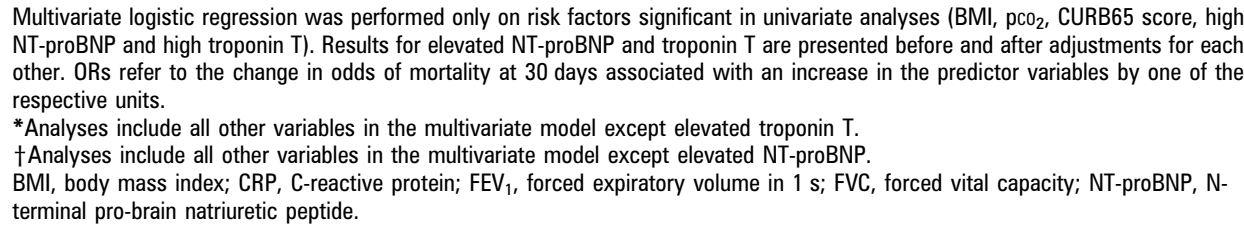 } \\
\hline
\end{tabular}

Although NT-proBNP and troponin T predicted mortality independently of other prognostic indicators, it remains unclear whether cardiac involvement is a direct cause of mortality or whether these biomarkers just reflect the severity of the exacerbation. In severe COPD, hypoxia and pulmonary vasoconstriction can cause pulmonary hypertension and right ventricular dysfunction. ${ }^{17}$ Tachycardia, ventilation-perfusion mismatch and respiratory muscle fatigue also contribute to cardiac stress, which may be exacerbated by an increased oxygen cost of breathing and increased left ventricular afterload from dynamic hyperinflation. Perhaps surprisingly, oxygen tension on arterial blood gas measurement was not associated with either elevated cardiac biomarkers or mortality. However, we cannot rule out the possibility that hypoxaemia earlier in the exacerbation may have contributed to these: many patients are treated with supplemental oxygen prior to hospitalisation and the arterial oxygenation measurements made on admission could have been influenced by this.

Alternatively, cardiac involvement may be due to a parallel process: many patients with COPD have co-existing coronary artery disease and systemic inflammation is associated with endothelial dysfunction and a procoagulant state. ${ }^{18}$ Hence, coronary ischaemia may be more likely to occur in the setting of an acute COPD exacerbation. ${ }^{19}$ However, none of the patients in our cohort had a clinical diagnosis of acute coronary syndrome. Moreover, there was only a weak correlation between C-reactive protein levels and NT-proBNP (Spearman rho=0.16, $\mathrm{p}=0.01$ ) and no correlation between C-reactive protein and troponin $\mathrm{T}$ ( $\mathrm{rho}=0.07$, $p=0.3$ ), indicating that the severity of the systemic inflammatory response was not a major determinant of cardiac involvement.

Elevated levels of NT-proBNP and troponin T did not predict deaths between 30 days and 1 year. This suggests that these biomarkers reflect the acute pathology of a severe exacerbation rather than general frailty. In keeping with this, NT-proBNP and troponin $\mathrm{T}$ predicted 30-day mortality independently of markers

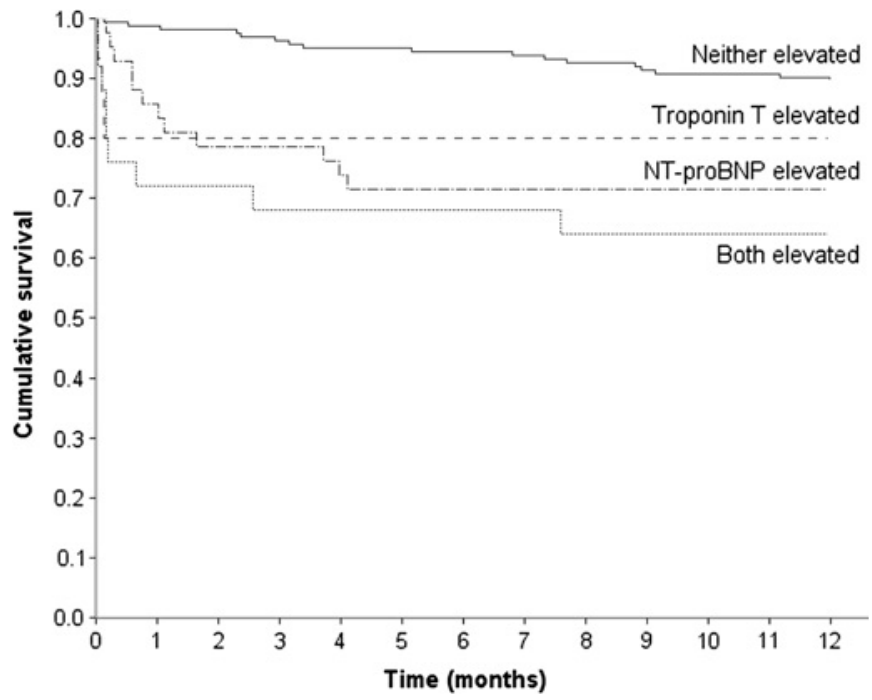

Figure 1 Kaplan-Meier survival curve for patients with acute exacerbation of chronic obstructive pulmonary disease (COPD) stratified according to cardiac biomarker status. Survival was worse in patients with both biomarkers elevated compared with patients with normal biomarkers (log-rank test, $\mathrm{p}<0.0001$ ). Survivals in patients with elevated $\mathrm{N}$-terminal pro-brain natriuretic protein (NT-proBNP) and cardiac troponin $\mathrm{T}$ alone are also significantly different from those in patients with neither biomarkers elevated (log-rank test, $p<0.001$ and $p=0.004$ respectively). 
Figure 2 Thirty-day mortality after exacerbation of chronic obstructive pulmonary disease (COPD) according to markers of cardiac dysfunction status (\%). Thirty-day mortality was significantly lower in patients who had normal N-terminal pro-brain natriuretic peptide (NT-proBNP) and troponin T levels (three deaths among 163 patients) compared with patients who had elevated troponin $\mathrm{T}$ alone $(2 / 14$, $\mathrm{p}=0.05)$, elevated NT-proBNP alone (7/42), $p=0.0007)$ and both elevated troponin T and NT-proBNP (7/25, $\mathrm{p}<0.0001)$. Mortality between groups was compared using $\chi^{2}$ test.

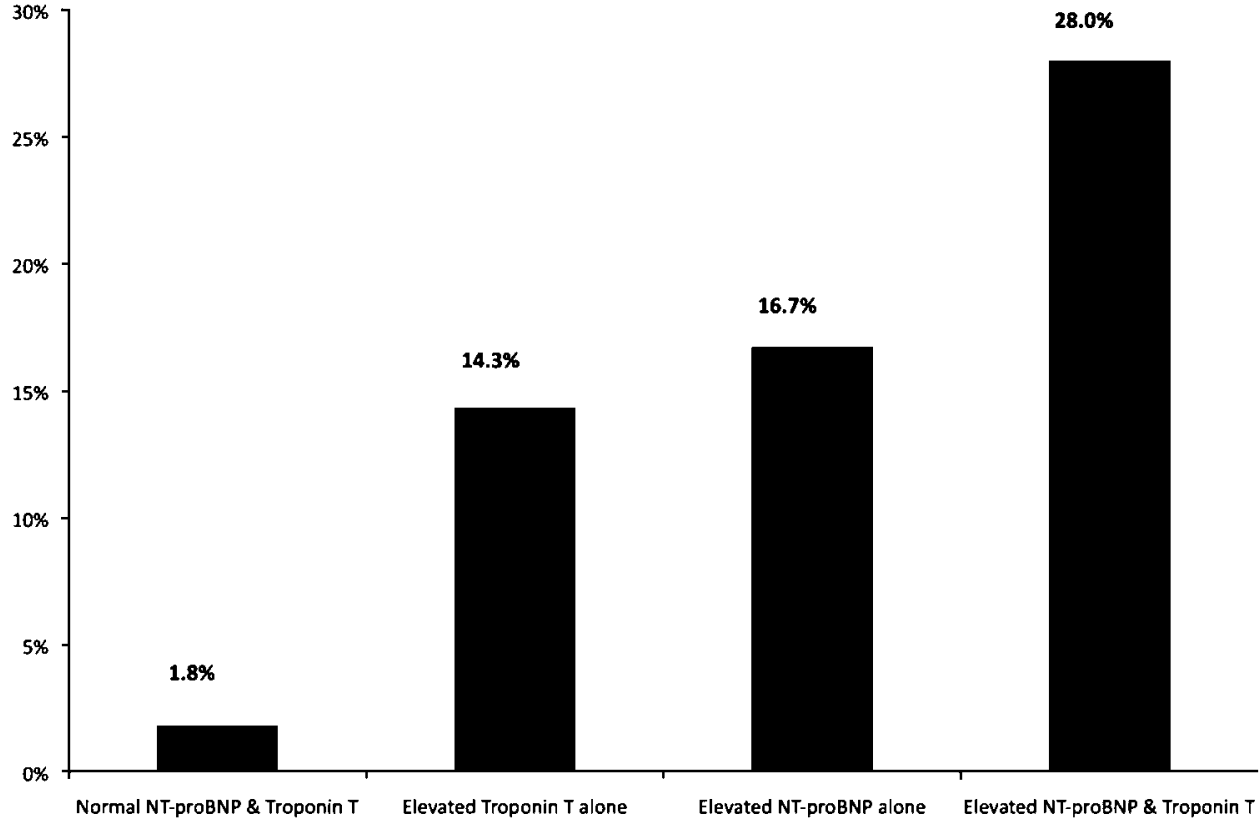

clinicians were not blinded to the results of the cardiac biomarkers and it is possible that patient treatment was influenced by these. However, since treatment would be expected to improve patient outcomes, any treatments would be more likely to cause an underestimation of the difference in mortality. Although we were unable to confirm COPD in a small number of patients, either because they did not have spirometry or because their spirometry did not meet strict GOLD (Global Initiative for Obstructive Lung Disease) criteria, excluding these patients from the analysis made no material difference to the findings. $^{29}$

Should patients with elevated NT-proBNP or troponin T but no clinical evidence of acute cardiac dysfunction be treated differently from patients with normal values? Increasing evidence suggests they should. A recent autopsy series of 43 consecutive patients who died within 24 h of hospitalisation for acute exacerbation of COPD found that cardiac failure was the leading cause of death. ${ }^{30}$ There is also observational evidence to support cardioprotective treatment with $\beta$-blockers in stable COPD. ${ }^{31} 32$ Patients receiving $\beta$-blockers appear to have a lower risk of COPD exacerbations ${ }^{33}$ and a lower mortality from exacerbations. ${ }^{33} 34$ Other cardioprotective treatments including statins and angiotensin-converting enzyme (ACE) inhibitors may also be beneficial in patients with COPD. ${ }^{35}{ }^{36}$ Our data suggest that cardiac involvement occurs frequently in acute exacerbations and that its presence predicts a poor prognosis. It is possible that active treatment of cardiac disease would improve outcomes, but we are not aware of any trials of acute cardiac treatment in this setting. Taken together, these findings point to an urgent need to investigate further the role of cardiac dysfunction and its treatment in COPD exacerbations.

In summary, elevated levels of NT-proBNP and troponin T predict early mortality in patients with acute exacerbations of COPD independently of other known prognostic factors. The pathophysiological basis of this is unknown, but the findings indicate the importance of cardiac dysfunction in these patients. NT-proBNP and troponin $\mathrm{T}$ may help clinicians to assess prognosis in exacerbations of COPD, but further research is needed to determine if they should influence treatment. 
Acknowledgements The authors wish to thank the study participants, Mark Chatfield for statistics support, and Manisha Cooray, summer student, for study co-ordination.

Funding The Waikato Medical Research Foundation and the Waikato Respiratory Research Fund

Competing interests None.

Patient consent Obtained.

Ethics approval This study was conducted with the approval of the the Northern Y Regional Ethics Committee of New Zealand.

Contributors All authors had full access to the original data and take responsibility for the integrity of the data and the accuracy of the analysis. All authors contributed to data collection and critical revision, made final decisions on all parts of the report and approved the final version of the submitted report. CLC, GDM, RJH designed the study. CLC, GDS, GDM, NCK, JDM, RJH enrolled patients and collected data. CLC, SCR, RJH undertook the analysis and drafting of the report.

Provenance and peer review Not commissioned; externally peer reviewed.

\section{REFERENCES}

1. Sin DD, Anthonisen NR, Soriano JB, et al. Mortality in COPD: role of comorbidities. Eur Respir J 2006:28:1245-57.

2. Holguin $\mathbf{F}$, Folch E, Redd SC, et al. Comorbidity and mortality in COPD-related hospitalizations in the United States, 1979-2001. Chest 2005;128:2005-11.

3. McGhan R, Radcliff T, Fish R, et al. Predictors of rehospitalization and death after a severe exacerbation of COPD. Chest 2007;132:1748-55

4. Ruiz-Gonzalez A, Lacasta D, lbarz M, et al. C-reactive protein and other predictors of poor outcome in patients hospitalized with exacerbations of chronic obstructive pulmonary disease. Respirology 2008;13:1028-33.

5. de Lemos JA, Morrow DA, Bentley JH, et al. The prognostic value of B-type natriuretic peptide in patients with acute coronary syndromes. N Engl J Med 2001;345:1014-21.

6. Kragelund C, Gronning B, Kober L, et al. N-terminal pro-B-type natriuretic peptide and long-term mortality in stable coronary heart disease. $N$ Engl $\mathrm{J}$ Med 2005:352:666-75

7. Kucher N, Printzen G, Goldhaber SZ. Prognostic role of brain natriuretic peptide in acute pulmonary embolism. Circulation 2003;107:2545-7.

8. Nagaya $\mathbf{N}$, Nishikimi $T$, Uematsu $\mathbf{M}$, et al. Plasma brain natriuretic peptide as a prognostic indicator in patients with primary pulmonary hypertension. Circulation 2000:102:865-70.

9. Tulevski II, Groenink M, van Der Wall EE, et al. Increased brain and atrial natriuretic peptides in patients with chronic right ventricular pressure overload: correlation between plasma neurohormones and right ventricular dysfunction. Heart 2001:86:27-30.

10. Alpert JS, Thygesen K, Antman E, et al. Myocardial infarction redefined-a consensus document of the Joint European Society of Cardiology/American College of Cardiology Committee for the redefinition of myocardial infarction. J Am Coll Cardiol 2000;36:959-69.

11. Mahajan N, Mehta $\mathrm{Y}$, Rose $\mathrm{M}$, et al. Elevated troponin level is not synonymous with myocardial infarction. Int J Cardiol 2006;111:442-9.

12. Harvey MG, Hancox RJ. Elevation of cardiac troponins in exacerbation of chronic obstructive pulmonary disease. Emerg Med Australas 2004:16:212-15.

13. Tabak YP, Sun XW, Johannes RS, et al. Mortality and need for mechanical ventilation in acute exacerbations of chronic obstructive pulmonary disease development and validation of a simple risk score. Arch Intern Med 2009; 169:1595-602
14. Chang CL, Sullivan GD, Karalus NC, et al. Predicting early mortality in acute exacerbation of chronic obstructive pulmonary disease using CURB65 scores. Respirology 2011;16:145-51.

15. Standardized lung function testing. Official statement of the European Respiratory Society. Eur Respir J Supp/ 1993;16:1-100.

16. Global Initiative for Chronic Obstructive Lung Disease GOLD. Global Strategy for the Diagnosis, Management, and Preventionof Chronic Obstructive Pulmonary Disease. 2009. http://www.goldcopd.com (accessed 27 Jun 2010)

17. Chaouat A, Naeije R, Weitzenblum E. Pulmonary hypertension in COPD. Eur Respir J 2008; 32:1371-85

18. Fabbri LM, Rabe KF. From COPD to chronic systemic inflammatory syndrome? Lancet 2007:370:797-9.

19. Donaldson GC, Hurst JR, Smith CJ, et al. Increased risk of myocardial infarction and stroke following exacerbation of COPD. Chest 2010:137:1091-7.

20. Bando M, Ishii $Y$, Sugiyama $Y$, et al. Elevated plasma brain natriuretic peptide levels in chronic respiratory failure with cor pulmonale. Respir Med 1999;93:507-14.

21. Tulevski II, Hirsch A, Sanson BJ, et al. Increased brain natriuretic peptide as a marker for right ventricular dysfunction in acute pulmonary embolism. Thromb Haemost 2001;86:1193-6.

22. Abroug F, Ouanes-Besbes L, Nciri N, et al. Association of left-heart dysfunction with severe exacerbation of chronic obstructive pulmonary disease: diagnostic performance of cardiac biomarkers. Am J Respir Crit Care Med 2006:174:990-6.

23. Stolz D, Breidthardt T, Christ-Crain M, et al. Use of B-type natriuretic peptide in the risk stratification of acute exacerbations of COPD. Chest 2008;133:1088-94.

24. Zakynthinos E, Kiropoulos T, Gourgoulianis K, et al. Diagnostic and prognostic impact of brain natriuretic peptide in cardiac and noncardiac diseases. Heart Lung 2008; 37:275-85

25. Brekke PH, Omland T, Holmedal SH, et al. Troponin T elevation and long-term mortality after chronic obstructive pulmonary disease exacerbation. Eur Respir J 2008; 31:563-70.

26. Fruchter 0, Yigla M. Cardiac troponin-I predicts long-term mortality in chronic obstructive pulmonary disease. COPD 2009;6:155-61.

27. Martins CS, Rodrigues MJ, Miranda VP, et al. Prognostic value of cardiac troponin in patients with COPD acute exacerbation. Neth J Med 2009:67:341-9.

28. Baillard C, Boussarsar M, Fosse JP, et al. Cardiac troponin I in patients with severe exacerbation of chronic obstructive pulmonary disease. Intensive Care Med 2003;29:584-9.

29. Pauwels RA, Buist AS, Calverley PM, et al. Global strategy for the diagnosis, management, and prevention of chronic obstructive pulmonary disease. NHLBI/WHO Global Initiative for Chronic Obstructive Lung Disease (GOLD) Workshop summary. Am J Respir Crit Care Med 2001;163:1256-76.

30. Zvezdin B, Milutinov S, Kojicic M, et al. A postmortem analysis of major causes of early death in patients hospitalized with COPD exacerbation. Chest 2009;136:376-80

31. Salpeter S, Ormiston T, Salpeter E. Cardioselective beta-blocker use in patients with reversible airway disease. Cochrane Database Syst Rev 2001:(2):CD002992.

32. Ormiston TM, Salpeter SR. Beta-blocker use in patients with congestive heart failure and concomitant obstructive airway disease: moving from myth to evidencebased practice. Heart Fail Monit 2003:4:45-54.

33. Rutten FH, Zuithoff NP, Hak E, et al. Beta-blockers may reduce mortality and risk of exacerbations in patients with chronic obstructive pulmonary disease. Arch Intern Med 2010;170:880-7.

34. Dransfield MT, Rowe SM, Johnson JE, et al. Use of beta blockers and the risk of death in hospitalised patients with acute exacerbations of COPD. Thorax 2008;63:301-5.

35. Soyseth V, Brekke PH, Smith P, et al. Statin use is associated with reduced mortality in COPD. Eur Respir J 2007:29:279-83

36. Mancini GB, Etminan M, Zhang B, et al. Reduction of morbidity and mortality by statins, angiotensin-converting enzyme inhibitors, and angiotensin receptor blockers in patients with chronic obstructive pulmonary disease. J Am Coll Cardiol 2006; 47:2554-60. 